\title{
Importantes mudanças na Revista de Psiquiatria do Rio Grande do Sul
}

\author{
Major changes in Revista de Psiquiatria do Rio Grande do Sul
}

\section{Conselho Editorial Local}

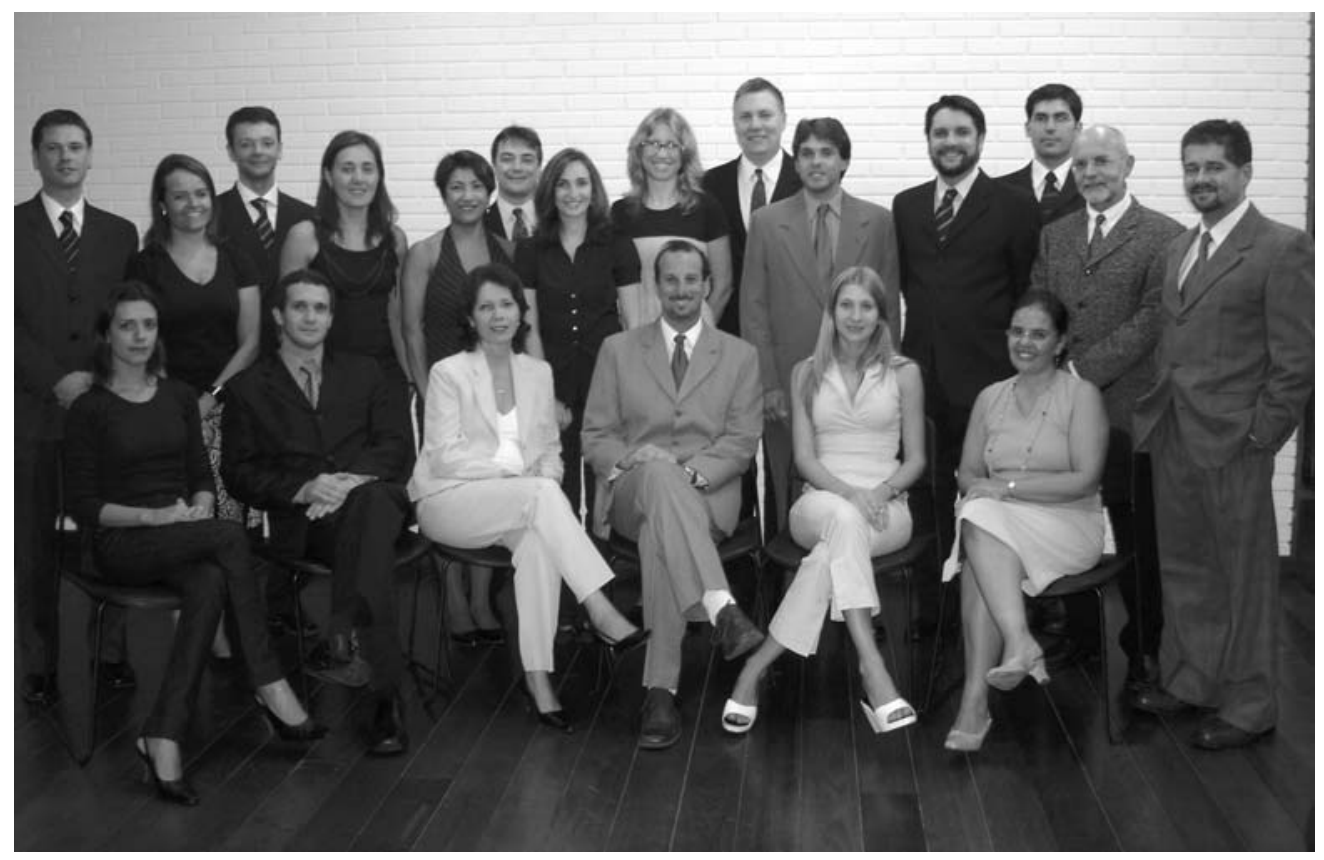

Membros do Conselho Editorial Local da Revista de Psiquiatria do Rio Grande do Sul. Em pé, da esquerda para a direita: Paulo de Tarso Fontes Neto, Gibsi Rocha,

Carlos Renato Maia, Maria Cristina Vasconcellos, Léia Maria Klöchner, Sérgio Louzada, Idete Bizzi, Lorena Caleffi, Luis Guilherme Streb, Mauro Terra, Felix Henrique Kessler, Alexei Gil, Carlos Alberto Salgado, Maurício Marx e Silva.

Sentados, da esquerda para a direita: Patricia Vilas Bôas, Jair Segal,

Carmem Keidann (editora), Flávio Shansis (editor), Carolina Blaya, Patrícia Picon.

Um periódico precisa estar em constante atualização e aperfeiçoamento, sob pena de, ao não fazer as adaptações necessárias, tornar-se obsoleto. Quando assumimos a editoria, no início de 2006, constatamos que muito havia sido feito pelas gestões anteriores, mas também observamos que, para seguir crescendo, profundas mudanças se faziam necessárias. Naquele momento, denominamos nossa gestão de "O desafio do crescimento”. O que passamos a enumerar a seguir é o resultado de um ano de intenso trabalho de todo o Conselho Editorial Local e que queremos agora compartilhar com nossos leitores.
- Mudança nos Conselhos Editoriais: a Revista de Psiquiatria do Rio Grande do Sul (RPRS) possuía um Conselho Editorial (que agora passa a chamar-se Conselho Editorial Local) muito qualificado, mas que se tornou reduzido para o número crescente de artigos recebidos nos últimos anos. Nossa primeira atitude foi a de aumentar o número de participantes nesse Conselho (mais que dobramos o número de membros), e também a de escolher para o Conselho Editorial Local especialistas em muitas subáreas da psiquiatria, criando assim a figura dos subeditores por área. Esses subeditores auxiliam sobremaneira os editores em 
relação à especificidade de cada artigo. Além das mudanças no Conselho Editorial Local, realizamos também alterações nos Conselhos Editoriais nacional e internacional (antes, denominados Conselhos Consultivos). Além de aumentarmos em muito o número de seus participantes, acreditamos que agora esses conselhos estão mais representativos das várias áreas de conhecimento psiquiátrico e de áreas afins. Foram convidados colegas brasileiros que se destacam, quer pela sua intensa publicação, quer pelo reconhecimento de seus pares. Finalmente, para o Conselho Editorial internacional, foram convidados colegas dos mais importantes centros universitários e instituições de vários países. Registramos nosso agradecimento a todos os colegas que fizeram parte tanto do Conselho Editorial Local, quanto do nacional e internacional, em gestões anteriores, pois a colaboração, dedicação e qualidade de cada um foi decisiva para a excelência que a Revista obteve e no impulso para novos desafios.

- Mudança na forma de avaliação dos artigos: criamos uma subcomissão que, ao longo de vários meses, elaborou um novo formulário de avaliação de artigos. Esse novo formulário é mais conciso e mais de acordo com os padrões internacionais de pareceres em revistas reconhecidas.

- Mudança nas regras de submissão de artigos: também foi criada uma subcomissão que elaborou cuidadosamente novas regras para os artigos que são enviados a nossa revista. Essas regras clarificam aos autores os critérios utilizados pelos Conselhos Editoriais quando da avaliação dos artigos. Também, adaptamos essas regras à especificidade de nossa revista, criando um tipo de artigo denominado "Comunicação teóricoclínica”. Esse tipo de artigo permite que, sem o rigor necessário a um artigo original ou a uma revisão sistemática, um autor possa expressar novas idéias acerca de um assunto e compartilhe suas reflexões com nossos leitores.

- Mudança no índice de recusa de artigos: dado o crescimento exponencial de artigos que a revista tem recebido (houve um aumento de $200 \%$ de artigos recebidos nos últimos três anos), fez-se necessária uma maior recusa de artigos. Isso, certamente, valoriza ainda mais a qualidade dos artigos que passam a ser publicados.

- Implementação de um sistema operacional totalmente online de submissão e avaliação de artigos: desde fevereiro último, o fluxograma da revista está totalmente online. A Diretoria da SPRS, em sintonia com nosso projeto de inovação, nos apoiou na aquisição de um software de gerenciamento denominado SGP/ SG1, de tecnologia nacional, que nos permite operacionalizar a revista de forma on-line. Os autores, ao submeterem seus artigos, podem acompanhar o andamento do seu artigo através da página de nossa revista: www.revistapsiqrs.org.br. Por outro lado, os pareceristas recebem imediatamente os artigos a serem avaliados e são lembrados regularmente do vencimento de seus prazos. Os editores e a secretaria têm acesso amplo a toda estrutura operacional da revista e, com isso, gerenciam muito melhor o andamento dos artigos. O resultado dos primeiros meses de utilização desse novo sistema de submissão on-line é uma maior agilidade, sem perder a qualidade nas avaliações. Nosso atual índice de tempo é, em média, 15 dias de avaliação de um artigo e de cerca de 27 dias entre submissão e/ou recusa. Isso é um padrão de alta qualidade em qualquer revista internacional, e demonstra nosso respeito aos autores que escolhem a nossa revista. Assim, eles sabem que, com agilidade, seus artigos são avaliados com o rigor necessário por, no mínimo, dois pareceristas.

- Layout renovado: a partir desse número, mudamos por completo o antigo layout gráfico da revista, que perdurou por 27 anos. Há algum tempo, já se debatia internamente que o layout estava ultrapassado e em desacordo com as principais publicações contemporâneas. O novo layout traz importantes mudanças: não apenas a fonte muda, mas o espaço na folha, a nova posição do resumo e abstract (a retirada de resumo e unitermos em espanhol), a nominata de autores, assim como a forma de sua titulação. Todas essas mudanças foram feitas para que a RPRS ficasse de acordo com o que outras revistas de qualidade apresentam como norma gráfica, seja no Brasil ou no exterior. Nosso sistema operacional on-line de submissão de artigos já se encontra adaptado a todas essas regras e os autores, ao enviarem seus artigos, adaptam-se automaticamente a elas.

- Manutenção e obtenção de novos indexadores: a revista segue sua política de reconhecimento da importância de indexadores nacionais e internacionais como forma de divulgar os artigos aqui publicados. Nacionalmente, cabe frisar que a RPRS segue sendo QUALIS A nacional pela CAPES (que é o padrão de avaliação de periódicos em nosso país), e em 2006 obtivemos nota A em todas as áreas da saúde avaliadas (Medicina I, Medicina II, Multidisciplinar e Saúde Coletiva). Seguimos mantendo a publicação da revista na íntegra em língua inglesa no site do SciELO internacional: www.scielo.br/rprs. Pretendemos fortemente seguir na busca de outros indexadores internacionais.

- Redefinição da linha editorial: a RPRS, desde o seu surgimento, caracteriza-se por uma linha editorial abrangente, "pluralista". Essa pluralidade no tema dos artigos publicados vem ao encontro da prática psiquiátrica realizada aqui em nosso meio. Poucas revistas no mundo, parece-nos, praticam a publicação de artigos tanto na linha de uma psiquiatria dita mais clínica, quanto artigos que abordem a prática 
psicoterápica. Disso, não queremos nos afastar. Entretanto, queremos afirmar ainda mais o nosso rigor quanto à qualidade dos artigos aprovados. Dentro da redefinição editorial, priorizamos a publicação de artigos originais, assim como comunicações breves, relatos de caso e comunicações teórico-clínicas. Deixamos espaço apenas para revisões que sejam sistemáticas e que, de fato, sejam relevantes para nossos leitores. Finalmente, a linha editorial atual, condizente com o que acontece em todas as grandes revistas, prioriza o papel dos editores como sendo o filtro inicial a partir do qual os artigos seguem ou não para pareceristas.
Enfim, os desafios do crescimento, a atualização e a busca de maior qualificação foram os principais motivadores para que o Conselho Editorial Local decidisse que o ano de 2006 seria o ano das mudanças. Gradualmente, e com um debate sereno e criterioso, essas mudanças foram sendo implementadas. O que apresentamos hoje é o resultado desse trabalho. Quisemos aqui compartilhar com nossos leitores "os bastidores" desta empreitada de editar a nossa Revista que, pela sua consistência, certamente é motivo de satisfação e orgulho para todos nós.

Aos colegas, uma ótima leitura! 